\title{
IMAGINÄRE UND WIRKLICHE PRÄSENZ RUSSLANDS IM NAHEN OSTEN IN DER ZWEITEN HÄLFTE DES 19. JAHRHUNDERTS
}

Will man die kulturellen, religiösen und geopolitischen Ziele Rußlands im Heiligen Land bzw. allgemein im Nahen Osten verstehen, besonders seit den vierziger Jahren des 19. Jahrhunderts, so muß man zuerst eine Analyse der Bedeutung dieses »heiligen Horts« in den russischen Kollektiv-Vorstellungen unternehmen.

\section{Jerusalem und Konstantinopel: Zwischen Mythos und Weltpolitik}

Für einen gläubigen Orthodoxen hatte der Name Jerusalem verschiedene Bedeutungen: zunächst vor allem das Jerusalem der Antike, das alte Welt-Zentrum, wo der heilige Tempel stand, später die von Jesus beweinte Stadt, wo er seine Sendung vom Thabor herabschreitend erfüllte, und schließlich das himmlische Jerusalem, Vorbild der irdischen Stadt. Das gesamte Leben eines jeden guten Orthodoxen läßt sich als ein Aufstieg zum himmlischen Jerusalem beschreiben, und dies ist der Grund, warum diese Stadt ständig im christlichen Bewußtsein gegenwärtig geblieben ist ${ }^{1}$. Die Liturgie hier auf Erden stellt die mystische Pilgerfahrt zum Ziel des Gläubigen, dem Himmelreich, dar. Das irdische Jerusalem, Ort der liturgischen Handlung, ist zwar ein unvollkommener Abglanz der

1 Diese Wahrnehmung Jerusalems ist allen Christen gemeinsam. Man findet ähnliche Ausführungen in verschiedenen Pilgerberichten aus dem Heiligen Land. So schrieb zum Beispiel der Bischof von Dijon, Landrieux, nachdem er die "Länder Christi« 1895 besichtigt hatte: "Iérusalem! Quelle évocation du passé! [...] Par-dessus tout, dominant des événements la promesse messianique, qui affirme, se précise, prend corps, évolue avec les siècles et attire peu à peu sur ce coin du monde les regards de l'humanité tout entière! [...] Jérusalem, c'est l'autel de la Rédemption. C'est là que le Sauveur du monde a fait le sacrifice d'expiation; là qu'il a signé le Testament Nouveau, en nous léguant l'Eucharistie et son Église [...] La Terre Sainte est un document«; vgl. Maurice LANDRIEUX, Aux pays du Christ. Études bibliques en Egypte et en Palestine, Paris 1895, S. 214. 
himmlischen Stadt, es ist aber der Weg, der uns durch die sakramentale Gegenwart des göttlichen Geistes dorthin führt ${ }^{2}$.

Diese Vorstellung von Jerusalem gab es nicht bloß in den theologischen und ikonographischen Texten oder in den politisch-ideologischen Konstruktionen, sondern auch in der allgemeinen Literatur und in der Folklore. In den Vorstellungen der ersten russischen Pilger war das Heilige Land ein weit entlegener Ort, gleichsam eine Insel, das Ende der Welt oder so etwas wie eine gartenumwobene Stadt, ein Paradies. Es war beizeiten auch ein Buch. Die Jerusalemer Pilgerfahrt verwies auf eine neue Bibellesung. Für die russischen Pilger des 7.14. Jhs. ${ }^{3}$ war Palästina das Land der biblischen Geschichte, und vor allem ein Beweis für die Existenz des im Orient gelegenen Paradieses ${ }^{4}$.

Diese volkstümlichen Vorstellungen nährten die folkloristischen russischen Texte. In einem Apokryph, Die Plauderei von Jerusalem, fragt David einen russischen Krieger, Bolot Boulatovitsch, nach den christlichen Symbolen und nach der Weltschöpfung. Laut Bolot ist Jerusalem die Mutter aller Städte, die Hagia Sophia ist die Mutterkirche aller Kirchen, denn dort befindet sich das Grab Jesu Christi; der Jordan ist der erste Fluß, denn dort fängt das Paradies an. David antwortet ihm: $»$ Rußland wird Jerusalem in Besitz nehmen, und in diesem Jerusalem wird es eine Hagia Sophia, eine apostolische Kirche, das Allerheiligste, geben. $\varkappa^{5}$ Der Gedanke, »Jerusalem in Besitz zu nehmen«, sich also nicht mit einem Pilgerstab, sondern mit dem Gewehr dorthin zu begeben, nicht nur allein, sondern zu Tausenden, war sehr verbreitet unter den russischen Pilgern des 19. Jahrhunderts ${ }^{6}$. Die mündliche Überlieferung hat bis ins 19. Jahrhundert noch andere bildhafte volkstümliche Vorstellungen beibehalten ${ }^{7}$.

2 Michel Evdokimov, Pèlerins russes et vagabonds mystiques, Paris 1987, S. 27. In den katholischen Darstellungen wird das himmlische Jerusalem als eine konkrete Veranschaulichung der biblischen Texte gezeigt. In der orthodoxen Ikonographie wird sie eher als Symbol dargestellt. Diese konkrete Darstellung der Lateiner (Katholiken) hat für die orthodoxe Spiritualität einen etwas fremden und sogar seltsamen Anschein. Für sie gilt es, sich in das Irrationale mittels der Betrachtung des himmlischen zu versenken. Siehe Alexander LIDOv, Obraz nebesnogo Ierusalima v vostotschkhristanskoj ikonografii. lerusalim $\mathbf{v}$ russkoj kulture (Das Bild des himmlischen Jerusalems in der orthodoxen Ikonographie. Jerusalem in der russischen Kultur), Moskau 1994, S. 15-24.

3 Kniga glagolemaja strannik (Die Pilgerfahrt des Erzmönchs Daniel ins Heilige Land Anfang des 12. Jhs.), Sankt Petersburg 1837. Dieser Bericht wurde zum Vorbild für die übrigen Pilgerberichte im Heiligen Land. Im 19. und 20. Jahrhundert gab es mehrere Ausgaben, und 1864 eine erste französische Übersetzung.

4 Roschdestvenskaja M.V. Obraz svjatoj zemli v drevnerusskoj literature. Ierusalim v russkoj kulture (Die bildliche Darstellung des Heiligen Lands in der altrussischen Literatur. Jerusalem in der russischen Kultur), Moskau 1994, S. 12.

5 Ibid. S. 12. Dieser apokryphe Text, der das Grab Jesu in der Konstantinopler Hagia Sophia, statt in der Jerusalemer Grabeskirche, ortet, zeigt, inwiefern das damalige russische Volksbewußtsein beide Städte verwechselte.

6 Antonij BOTCHKOV (Erzmönch), Russkie poklonniki $\mathrm{v}$ Ierusalime (Die russischen Jerusalempilger), Moskau 1875, S. 96. Derselbe Autor berichtet über eine Unterhaltung zwischen einem Bauernpilger und einem Kriegsveteranen von 1812. Der Bauer sagt: »Die 
Vom 16. Jahrhundert an unternahm der russische Staat die Gründung von einem zweiten Jerusalem auf russischem Boden. Der erste Versuch in diese Richtung war der Bau der Auferstehungskathedrale, des »Allerheiligsten« nach dem Vorbild der Jerusalemer Grabeskirche innerhalb des Kremlins ${ }^{8}$. Erbauer war der Zar Boris Godunow (1598-1605). Um 1660 wurde in der Nähe von Moskau das Kloster des Neuen Jerusalems durch den Patriarchen Nikon errichtet. Nikon wurde aufgrund seiner religiösen Reformen, die das russische Schisma des Raskols hervorgerufen haben, bekannt ${ }^{9}$. Peter der Große hatte den Plan, das Grab Christi nach Sankt Petersburg zu überführen ${ }^{10}$. Auf diese Weise nahm Jerusalem als antike, heilige oder himmlische Stadt über eine längere Zeit hinweg einen wichtigen Platz in den russischen Kollektivvorstellungen ein, abgesehen davon ob diese nun volkstümlich oder politisch waren.

Doch neben Jerusalem zeichnet sich noch eine andere Stadt ab: Konstantinopel. Die Bedeutung dieser Stadt beruhte ebenfalls auf drei Aspekten: eine an die Kaiseridee gebundene Stadt, eine Hauptstadt der Slawen sowie eine Stadt mit einer geopolitischen Bedeutung aufgrund ihrer Lage an der Meerenge. Die gesamte russische Geschichte zeigt, daß der Gedanke an die Eroberung und an den Besitz von Konstantinopel ein Grundthema der russischen Politik und Ideologie wurde und blieb. Nach der Einnahme Konstantinopels durch die Türken (1453) und nachdem die russische Kirche die Unionsdekrete des Konzils von FerraraFlorenz (1438-1439) zurückgewiesen hatte, verwendete der Mönch Philotheos von Pskov den Ausdruck des »dritten Roms«. Früher, so behauptete er, hätte es zwei christliche Weltzentren gegeben: zuerst das Rom der Antike, das infolge seiner Unterdrückung der christlichen Wahrheit gefallen ist, dann Byzanz. Jedoch hätten die byzantinischen Herrscher die Christenheit verraten, da sie die Union mit der lateinischen Kirche 1439 anerkannt hatten. Deswegen wäre das christliche Byzanz von den Türken erobert worden, und Moskau zum neuen Weltzentrum geworden. Die Orthodoxie bilde die einzige »reine« und wahre

Russen müssen Jerusalem erobern, man darf das Klima und die Krankheiten nicht fürchten [...] Es ist kein Zufall, daß das erste russische Regiment den Namen der Verklärung trägt, und daß die Ziffer 88 auf der Uniform der Soldaten dieses Regiments steht, denn diese Ziffer ist die des 88 . Verses des Matthäusevangeliums, worin der Erlöser gegen die Pharisäer spricht, und vom Himmelreich, welches dem auserwählten Volk versprochen ist. « S. 25.

7 Zum Beispiel gibt es in Jerusalem eine Pforte, die direkt in die Hölle führt. Von Rußland aus kann man durch eine unterirdische Pforte nach Jerusalem gelangen. Siehe BotchKov, Die russischen Jerusalempilger, S. 30; und Antonij MEdVEDEv (Mönch), Vospominanija duchevnich vpetschatlenij pri poklonenii svjatine na Vostoke (Geistliche Erinnerungen im Heiligen Land), Moskau 1880, S. 1f.

8 lerusalim v russkoj kulture (Jerusalem in der russischen Kultur), Moskau 1994, S. 154-171.

9 Ibid. S. 174-181.

${ }^{10}$ Sergei I. PONOMAREV, lerusalim i Palestina v russkoj literature, nauke, schivopisi i perevodach (Jerusalem und Palästina in der Literatur, in der Wissenschaft, in der Kunst und in den russischen Übersetzungen), Sankt Petersburg 1877, S. XVI. 
Christenheit; sie wäre die einzige rechtmäßige Erbin des antiken Roms sowie des christlichen Byzanz. Niemals würde es ein viertes Rom geben ${ }^{11}$. Die Auslegungen dieser Theorie zwischen dem 16. und dem 19. Jahrhundert machten die russischen Prinzen und danach die Zaren zu den Allein-Verantwortlichen für das Schicksal der Orthodoxie, sowie zu direkten Erben der oströmischen Kaiser ${ }^{12}$, was ihren Wunsch Byzanz zurückzuerobern bestimmen konnte. Dies mag ihren Wunsch nach der Wiedereroberung von Byzanz verständlich machen ${ }^{13}$.

"Die Idee vom dritten Rom findet ihren Ursprung in einer anderen, viel älteren Theorie, die von den Orthodoxen die »Theorie der Symphonie der Gewalten« genannt wurde. Staat und Kirche seien dieser Theorie nach zwei Gaben, die Gott der Menschheit verliehen hat, also zwei Bestimmungen der Wirklichkeit, die aus einer einzigen Quelle entspringen, und zwar dem Willen Gottes. Deshalb muß es zwischen diesen beiden eine vollkommene "Harmonie« geben, so daß eine der anderen behilflich sein soll, aber ohne daß die Freiheit und Autonomie in der eigenen Sphäre genommen sei. Der Kaiser hat in dieser Vorstellung eine wichtige Stellung inne: "Als der Kaiser dem Christentum beitrat, hat die Kirche auf ihn ihre Gaben mittels des Sakralen ausgegossen; von da ab hat sie ihn geliebt wie ihren Gesalbten, nicht nur als Staatschef, sondern auch als Träger eines besonderen politischen Charismas, als der von Christus gezeichnete Gatte der Kirche [...]. Die Kirche bestand besonders stark auf ihren Bund mit dem Staat, insofern letzterer in ihrem Dienste stand. Die Kirche betrachtete es als eines ihrer besonderen Merkmale, daß sie einen orthodoxen Herrscher zum Oberhaupt hatte. Dieser war das Symbol der Welteroberung durch das Kreuz, des Aufbaus des Reichs Gottes auf Erden«. Siehe, für die Theorie der Symphonie: Sergei 1. Bulgakov, Pravoslavie (Die Orthodoxie), Moskau 1991, S. 332-334.

${ }^{12}$ Die Idee der "Verantwortung der russischen Erben« wurde auch mehrere Male von außerrussischen Kreisen verbreitet. So z.B. vermutet Fedor I. Uspenskij, daß römischkatholische Kreise zu Anfang des 16. Jhs. die Theorie des dritten Roms angeregt hätten, um ein Bündnis gegen die Türkei hervorzurufen. Siehe Fedor I. USPENSKIJ, Kak voznik i razvivalsja $v$ Rossii Vostotschnij vopros (Wie die Orientfrage aufkam und sich in Rußland entwickelt hat), Sankt-Petersburg 1887, sowie andere Arbeiten desselben Autors. Nikolai F. Kapterev zeigt, daß im 16.-18. Jh. die Patriarchen von Jerusalem den russischen Zaren gegenüber darauf bestanden, daß letztere die Auserwähiten der Vorsehung für die Unterstützung der Orthodoxie und für den Kampf gegen die Türken seien. Sie taten dies anläßlich der alljährlichen Bitten um Geldhilfen. Jede türkische Niederlage, jeder innertürkische Konflikt waren für die griechischen Patriarchen Vorzeichen des Untergangs des türkischen Reichs. Moskau sollte bei diesem Anlaß das Erbe der griechischen Kaiser übernehmen. Siehe Nikolai F. KAPTEREV, Snoschenija Ierusalimskich patriarchov s russkim pravitelstvom so vtoroj polovini XVI do konza XVIII stoletija (Die Beziehungen der Jerusalemer Patriarchen mit der russischen Regierung, von der zweiten Hälfte des 16. bis zum Ende des 18. Jahrhunderts), Sankt Petersburg 1895, S. 358-373, 460-368.

${ }^{13}$ Im Laufe des 16.-20. Jhs. wurde die Theorie des Mönchs Philotheos durch den Staat und durch die russische Intelligentsia aktualisiert, in neue Kontexte versetzt, benutzt und ausgenutzt. Die anfängliche Idee des dritten Roms wurde in die Formel »Moskau ist das dritte Rom « umgesetzt. Die wissenschaftlichen Auslegungen dieser Formel waren meistens messianisch, universalistisch, imperialistisch, jedenfalls von der ursprünglichen mittelalterlichen Deutung sehr entfernt. In seinem jüngsten Werk versucht N.N. Sinicina den historischen Kontext der Philotheischen Theorie an den Tag zu legen. Er versucht zugleich die verschiedenen Auslegungen der Formel »Moskau ist das dritte Rom» abzubauen und deren tiefere Hintergründe im Laufe des 16.-20. Jhs. klarzulegen. Siehe 
Das, ob authentisch oder falsch, Testament Peters des Großen (1682-1725) wurde zu einem wichtigen Meilenstein, der zu der Begründung des Mythos »Konstantinopel für uns Russen« führte. Dieses Testament hat die Politik der Nachfolger Peters auf diesem Gebiet bestimmt. Im Abschnitt 9 wird empfohlen, "so nah wie möglich an Konstantinopel und an Indien heranzukommen, denn der dortige Besitzer wird der wahre Weltherrscher sein ${ }^{14}$.

Ende der siebziger Jahre des 17. Jahrhunderts faßte Katharina II. (1762-1786) ihren "griechischen Plan«. Über diesen Plan hat es verschiedene historiographische Debatten gegeben ${ }^{15}$. Wir möchten hier lediglich unterstreichen, daß die wichtigsten Dokumente dieser Debatte den Wunsch Katharinas II. demonstrieren, »die Türkei ganz zu zerstören und das alte griechische Kaiserreich zugunsten seines zweiten Enkels, des Großfürsten Konstantin wiederherzustellen « ${ }^{16}$.

So entstand in jener Zeit ein neues Konzept russischer Außenpolitik: Die Achse Sankt Petersburg - Konstantinopel - Jerusalem wird die Orientpolitik Rußlands im 19. Jahrhundert bestimmen, zu einer Zeit in welcher das Orientproblem zu einem der Hauptprobleme der Weltpolitik mehrerer europäischer Staaten wird. Was Rußland betrifft, fußt das Orientproblem auf drei Grundideen:

1. einer religiösen Idee: die Notwendigkeit, Konstantinopel zu befreien und den Orthodoxen des Osmanischen Reichs zu helfen;

2. einer nationalen Idee: die Befreiung der slawischen Brüder;

3. einer geopolitischen Idee: den Zugang zu den Meerengen gewinnen.

Durch das ganze 19. Jahrhundert hindurch wurde das Orientproblem vom Staat und von der russischen Intelligentsia durchdacht, wobei die Grundideen unverändert blieben. Paradoxerweise war es nicht die kaiserliche Gewalt, welche an der Spitze der Bewegung »für Konstantinopel« stand. Diese Politik ist von einer Idee des Grafen Viktor Kotschobey inspiriert, der 1802 für den Zaren Alexander I. (1801-1825) ein Memorandum über die Türkei und die russische Politik ihr gegenüber verfaßte. Laut dem Grafen »kann Rußland nicht anders vorgehen, als im Einvernehmen mit Frankreich und Österreich das Land aufzuteilen, oder aber mit allen Mitteln die Gefahr der Zerstückelung zu verhindern.« Für Kot-

Nina B. SINICINA, Tretij Rim (Das Dritte Rom), Moskau 1998.

${ }^{14}$ Die russische Historiographie spricht diesem Dokument jegliche Authentizität ab. Meistens wird angenommen, daß dieser Text von einem am Hof der Prinzessin Elisabeth (17411762) lebenden Franzosen verfaßt worden ist oder etwas später, am Anfang des 19. Jhs., nach Sergei SCHUBINSKIJ, Mnimoe zavesanie Petra (Das falsche Testament Peters des GroBen), Sankt Petersburg 1877, S. 10.

${ }^{15}$ Siehe das kürzlich erschienene Buch über dieses Thema: Vek Ekaterini II. Dela balkanskie (Das Zeitalter der Katharina II. Die balkanischen Angelegenheiten), Moskau 2000.

${ }^{16}$ Ibid. S. 212. Dieser Gedanke war in der damaligen Gesellschaft geläufig. 1790 richtete der Dichter Gavriil R. Derjavin in einem Gedicht folgende Bitte an Katharina II: „Sie möge das Heilige Grab befreien und Konstantinopel dem Konstantin übergeben.« 
schobey war die zweite Alternative vorzuziehen: »unabhängig davon, daß Rußland überhaupt keine Gebietserweiterung anstrebt, gibt es keine ruhigeren Nachbarn als die Türken, und die Erhaltung dieses Gegners soll künftig zur Grundregel unserer Politik werden. ${ }^{17}$

Eigentlich ist es die russische Intelligentsia, welche mit Hilfe der Staatsbeamten und Diplomaten den Mythos, nach dem Dostojevskischem Ausspruch: »Zargrad gehört uns Russen«, gegründet, bzw. rekonstruiert hat. In den politischreligiösen Ideen der russischen Intellektuellen findet man eine seltsame Mischung von rationellen Gedankengängen und von historischen Trugbildern, eine Mischung von Realität und Mythos. Für den Dichter Fedor Tuttschev und für die erste Generation der Slawophilen der Jahre 1830-1850 (unter ihnen der Historiker und Professor an der Moskauer Universität Mikhail Pogodin) gehörte es zu der Ehre Rußlands, daß der Zar der Messe in der Hagia Sophia beiwohnte, daß das Kreuz den Halbmond ersetzte ${ }^{18}$ und daß Rußland alle Orthodoxen beschützte und den religiösen Gedanken verteidigte. Pogodin schrieb: „Alles ruft uns

${ }^{17}$ Zitat aus Sergei Goriainow, Le Bosphore et les Dardanelles, Paris 1910, S. 49. 1829, am Vorabend der Unterzeichnung des Andrinopel-Vertrags (2.-4. September 1829), wurde dieser Gedanke vom russischen Außenminister, dem Grafen von Nesselrode, und vom Regierungsrat Daschkow aufgenommen. In ihrem Bericht an den russischen Geheimrat unterstrichen sie, daß »es weit vorteilhafter für Rußland sei, für die Beibehaltung des Osmanischen Reichs zu sorgen, als dasselbe zugrunde gehen zu lassen.« Um 1839, befürwortete Nikolaus I. euneut die Beibehaltung des statu quo in Südeuropa, und nicht die Auflösung der Türkei. Siehe GORIAINOW, Le Bosphore et les Dardanelles, S. 27, 37; und Joseph HaJJaR, L'Europe et les destinées du Proche-Orient (1815-1848), Paris 1970, S. 87-89. 1878 blieb die russische Armee vor den Toren Konstantinopels stehen. Zar Alexander II. zog es vor, die Stadt nicht einzunehmen. Diese Politik blieb das ganze 19. Jh. lang dieselbe. Das in der Orient-Politik fortgesetzte Konzept des Grafen Kotschobey wurde in der russischen Gesellschaft kritisiert. Der bekannte Historiker Sergej Solowiew, Vater des Wladimir Solowiew, warf Kotschobey vor, die These von Montesquieu allzu wörtlich genommen zu haben, wonach ses vorteilhafter sei für einen Staat, schwache Länder als Nachbarn zu haben [...]. Sind die Türken schwach, ist es dann nicht für uns ein Nachteil, sie bewahren zu müssen? Wäre ein Krieg für die Beibehaltung der Türkei nicht weniger gefährlich für uns als ein Krieg gegen die Türkei? « Die Russen, schreibt Solowiew, hätten ihr heiliges Versprechen des Schutzes der Orthodoxen in der Türkei vergessen. Zitiert nach GORIAINOW, Le Bosphore et les Dardanelles, S. 49-50. S. M. SOLOWIEW, Vostotschnij vopros (Das Orientproblem), in: Sotschinenija (Gesammelte Werke), Sankt Petersburg 1882. Der russische General Alexei N. Kuropatkin behauptete, daß das Konzept von Kotschobey RuBland daran gehindert hätte, die Meerengen zu besetzen, um seine geopolitischen Ziele zu verwirklichen. Alexei N. KUROPATKIN, Rossija dlja russkich (Rußland für die Russen), Sankt Petersburg 1910, Bd. II, S. 25.

${ }^{18} \mathrm{Im}$ Volksmund gibt es eine Überlieferung, wonach eingeschlafene griechische Priester in einem geheimen Ort der jetzigen Moschee Hagia Sophia verborgen sind. Sie warten auf die Rückereroberung Zargrads durch christliche Krieger, um die Heilige Liturgie wieder aufzunehmen. Ilja BERESIN, Posesenie zarigradskich dostoprimetschatelnostej vo vremja prebivanija v Konstantinopole velikogo knajazja Konstantina Nikolaevitscha v 1845 (Der Besuch des GroBfürsten Konstantin Nikolaevitsch in Zargrad im Jahre 1845), Sankt Petersburg 1854, S. 48. 
nach Konstantinopel: die Geschichte, die Pflicht, die Ehre, die Sicherheit, die Traditionen, die Vernunft und die Wissenschaft, die Dichtkunst, die Verwandtschaft, die Dankbarkeit, der Glaube, die Freunde, die Gegner, das Gedenken, die Vergangenheit, die Gegenwart, und sogar die Zukunft - und wir werden in Konstantinopel sein. « $^{19} 1849$ schrieb Tuttschev, daß zwei gottbestimmte Ereignisse eine neue Epoche für Europa einleiten würden:

1. Die endgültige Gründung des großen Orthodoxen Reichs, in einem Wort, des Rußlands der Zukunft, das durch die Einnahme Österreichs und der Rückkehr Konstantinopels zustande kommen wird; 2. die Union beider Kirchen, vom Orient und vom Okzident. Anschließend kann man sagen: der orthodoxe Kaiser in Konstantinopel, Oberhaupt und Beschützer Italiens und Roms, der orthodoxe Papst in Rom, Untertan des Kaisers ${ }^{20}$.

Nach dem Krimkrieg in den 1860er Jahren hat sich der Vorwand des "Schutzes der Christen« in einen notwendigen »Schutz aller Slawen« gewandelt, und zwar unter dem Einfluß der Entfaltung der nationalistischen Bewegungen im Balkan. Ohne zu schematisieren, darf man feststellen, daß wenn diese beiden Vorwände auch gleichzeitig existierten, die zweite Generation der Slawophilen (Iwan Aksakov, Alexander Kireev) und die dieser Bewegung nahestehenden Denker, Nikolai Danilevski, Konstantin Leontiev, sowie Fedor Dostojevski, das Problem der Befreiung der slawischen Brüder stärker betonten. ${ }^{21}$.

Der russische Panslawist Danilevski war Beamter im Kriegsministerium und Autor des Werks »Rußland und Europa« (1869). Die antike Stadt, schrieb er, hat mehrere Namen getragen: Byzanz, Konstantinopel, Istanbul. Sie sollte nun den slawischen Namen Zargrad annehmen und zu Rußland gehören. Besitze man Konstantinopel, bedeute das soviel wie die Grenzen zu erweitern und die Hauptrolle im Raum des Schwarzen Meeres zu spielen; wichtiger jedoch wäre im moralischen Sinn das Zentrum der Orthodoxie und der menschlichen Tradition, was Rußland ermächtigen würde, einen Einfluß auf alle Länder des Orients auszuüben. Auf diese Weise würde Rußland das historische Erbe beanspruchen können, um das Orientreich wiederherzustellen. Allerdings sollte Konstantinopel »nicht die Hauptstadt Rußlands« werden. Allein Moskau hätte das Recht, die

${ }^{19}$ Zitat nach Boris DANZIG, Blischnij Vostok (Der Nahe Osten), Moskau 1976, S. 296.

${ }^{20}$ Literatumoe nasledie (Das literarische Erbe), Moskau 1988, v. 97 (I), S. 192. Im selben Zeitraum hat der Autor für seine politischen Aufsätze unvollendete Notizen auf französisch hinterlassen: "Der Zar ist Kaiser von Rußland in seiner Eigenschaft als Kaiser des Orients [...] Was die Türken anbelangt, so haben sie den orthodoxen Orient besetzt, um ihn den Westeuropäern vorzuenthalten [...] während dieser Zeit organisiert sich das rechtmäßige Kaiserreich. Das Kaiserreich ist eins; die orthodoxe Kirche ist die Seele des Kaiserreichs, die slawische Rasse ist dessen Leib. Sollte Rußland nicht zum Kaiserreich gelangen, so würde es scheitern. Das Orientreich: Dies ist das endgültige Rußland.« Ibid. S. 215.

${ }^{21}$ Die Slawophilen der zweiten Generation waren meistens Träger des Nationalgedankens. Leontiev jedoch, der in den sechziger Jahren des 19. Jahrhunderts nach einem längeren Aufenthalt als Diplomat in den Balkanländern auf der Seite der Slawophilen war, änderte seine Meinung in den achtziger Jahren und wurde zum Befürworter des religiösen Gedankens. 
»Heilige Stadt« zu sein. Das Schicksal Konstantinopels wäre es, Hauptstadt der slawischen Föderation zu werden ${ }^{22}$.

Demgegenüber befürwortete Leontiev, Schriftsteller, Diplomat und Autor des Buchs »Der Orient, Rußland und die Slawen « (1882), einen slawischen Bund unter der Oberherrschaft des russischen Zaren: Er sah »das russische Reich mit seiner neuen Hauptstadt Kiew, und Rußland als Haupt der großen Union des Orients mit der neuen kulturellen Hauptstadt auf dem Bosphorus. « Diese neue Welt, die auf den politischen, ideologischen und kulturellen Werten von Byzanz gründete, war einerseits dazu berufen, Rußland zu mvverjüngen`, die Macht der Zaren zu verstärken, und andererseits zur Festigung der öffentlichen Sicherheit beizutragen. ${ }^{23}$

In seinem »Tagebuch eines Schriftstellers« behauptete Dostojevski 1876 "früher oder später wird Konstantinopel unser sein $\aleph^{24}$, denn Rußland allein hätte in seiner Eigenschaft als orthodoxe Großmacht und als berufenes Zentrum der Slawen das Recht, diese Stadt zu besitzen. »Es wird eine wahrhaftige Verklärung der Wahrheit Christi werden, die im Orient erhalten blieb; es wird eine neue Verklärung des Kreuzes Christi werden, eine Verklärung der Orthodoxie, dessen Haupt von jeher Rußland gewesen ist $\ll^{25}$.

1877 führt er seine Gedanken folgendermaßen aus:

Konstantinopel soll unser sein, wir sollen es von den Türken erobern, es soll für immer unser sein [...]. Rußland hat Konstantinopel zu besetzen, einzig und allein weil Rußland die Sendung hat, das slawische Problem zu lösen, und noch aus einem anderen viel wichtigeren Grund: Rußland hat die Orientfrage zu lösen, und diese kann nur in Konstantinopel gelöst werden [...]. Die Orientfrage liegt im wesentlichen im Schicksal der Orthodoxie. Das Schicksal der Orthodoxie ist an das Schicksal Rußlands gebunden ${ }^{26}$.

Die gesamte intellektuelle Elite teilte bei weitem nicht die Träumereien der Slawophilen und Dostojevskis. Vassili Jukovski, Dichter und Hauslehrer der Kinder des Zaren Nikolaus I., schrieb beispielsweise seinem Schüler, dem Großfürsten Konstantin Nikolajevitsch um 1845, im Anschluß an seiner Reise nach Konstantinope ${ }^{27}$ :

${ }^{22}$ Nikolai DANILEVSKI, Rossia i Evropa (Rußland und Europa), Sankt Petersburg ${ }^{2} 1871$, S. 197f. Danilevski war gegen den Plan, aus Konstantinopel eine freie Stadt zu machen. Die Gefahr bestand darin, daß es zu einem Zentrum der katholisch-jesuitischen, sowie protestantischen und sogar revolutionären Propaganda würde. Nikolai DANILEVSKI: Sbornik politichiskich i ekonomitschiskich statey (Sammlung politischer und ökonomischer Artikel), Sankt Petersburg 1890, S. 137.

${ }^{23}$ Konstantin LEONTIEV, Vostok, Rossia i slavjanstvo (Der Orient, Rußland und die Slawen), zitiert in: R. STRELKOV, Rossia, Zargrad i prolivi (Rußland, Zargrad und die Meerengen), Petrograd 1915, S. 83, 88.

${ }^{24}$ Fedor DOSTOJEVSKI, Dnevnik pisatelaja za 1877 , Polnoe sobranie sotschinenij v 30 tomach (Tagebuch eines Schriftstellers, Gesammelte Werke), Leningrad 1982, Bd. 24, S. 48.

${ }^{25}$ Ibid. S. 50.

${ }^{26}$ Ibid. Bd. 25, S. 65-74.

${ }^{27}$ In Konstantinopel hatte der Großfürst den Patriarchen Konstantin getroffen, der seine Rede mit der Forderung nach russischer Hilfe beendete, damit »die Orthodoxie sich bis 
[...] in Sankt Petersburg haben Sie Zargrad im Traum gesehen. Ihr Traum hat eine poetische Eigenschaft, in der Wirklichkeit war es aber bloß ein Traum, und ich wünschte, daß dieser Traum sich nie verwirklichen wird. Dieses Byzanz ist eine fatale Stadt [...]. Zargrad, zwischen zwei Meeren liegend, voll von historischen Erinnerungen, hat (fuir uns Fremde) das Recht, die Hauptstadt eines großen Reichs zu sein; aber in diesem Fall würden die orthodoxen Zaren hinter den Mauem des Serails der Sultane verschwinden [...]. Nein, Gott behüte Sie, Rußland in ein byzantinisches Reich zu verwandeln ${ }^{28}$.

Ebensowenig war Wladimir Solowiew mit der Idee der Eroberung Konstantinopels einverstanden:

Rußland ohne Zargrad, schrieb er, soll innerhalb seiner natürlichen Grenzen versuchen, ein christliches Königreich im wahren Sinne zu sein: ein Königreich der Wahrheit und des Mitleids, in diesem Fall wird ihm alles andere gegeben ${ }^{29}$.

Man sieht also, daß gegen Ende des 19. Jahrhunderts das Problem von Konstantinopel nicht mehr im Vordergrund stand. In den achtziger Jahren wurden die religiösen Belange durch andere, geopolitische und wirtschaftliche, abgelöst. Der liberale Publizist Sergei Ugakov hat dies vortrefflich hervorgehoben: "Russland sollte sich die Meerengen unterwerfen, um den freien Zugang vom Schwarzen Meer zum Mittelmeer und nach Asien für seine strategische Verteidigung zu erlangen. ${ }^{30}$ Der Publizist widerlegte die Idee einer militärischen Eroberung Konstantinopels. Der russische Außenminister N.K. Giers hat die Ansichten der russischen Diplomaten in den 1890er Jahren gegenüber seinem französischen Kollegen Ribot beschrieben. Letzterer fand, daß die russische Po-

nach Zargrad erstrecken könne«. Bersin, ein Archäologe und Schriftsteller, der den Großfürsten auf seiner Reise begleitete, wies auf die Bedeutung hin, die der Besuch Konstantins, Sohn des russischen Zaren, in einer alten Hauptstadt von Konstantin für die orthodoxe Bevölkerung besaß. BERESIN, Der Besuch des Großfürsten Konstantin Nikolaevitsch, S. 90.

${ }^{28}$ Zitiert in: STRELKOV, Rußland, Zargrad und die Meerengen, S. 50f.: Brief von Jukovski an den Großfürsten Konstantin Nikolajevitsch.

${ }^{29}$ Wladimir SolowIEW, Sobranie sotschinenij (Gesammelte Werke), Sankt Petersburg 1901, Bd. 6, S. 480.

${ }^{30}$ Zitiert in: Istorija vneschej politiki Rossii, vtoraja polovina XIX veka (Geschichte der russischen Außenpolitik in der zweiten Hälfte des 19. Jahrhunderts), Moskau 1999, S. 325. S. Goriainow hat in seinem, auf bislang unbekanntem russischen Archivmaterial beruhenden Werk Der Bosphor und die Dardanellen (russisch: Sankt Petersburg 1907; französisch: Paris 1910) den Kampf Rußlands um den Zugang zu den Meerengen beschrieben. Während des Ersten Weltkriegs, wie bereits vor 1914, war die Frage der Meerengen von großer Bedeutung für die öffentliche Meinung. Den besten Beweis für das Interesse der russischen Gesellschaft an dieser Frage bringen die verschiedenen Werke, die in jenen Jahren veröffentlicht wurden: neben Goriainow, G. ARKTUR [Iwan DUSINSKIJ], Osnovnie voprosi vneschej politiki Rossii (Die Hauptfragen der russischen Außenpolitik), Odessa 1910; Alexei KUROPATKIN: Rossia dlja russkich (Rußland für die Russen), Sankt Petersburg 1910; STRELKOV, Rußland, Zargrad und die Meerengen. Zahlreiche Notizen, geheime diplomatische und militärische Berichte wurden unmittelbar nach der Oktoberrevolution veröffentlicht, um das Zarenregime in Verruf zu bringen. Siehe Evgenij A. ADAMOV, Konstantinopl i prolivi (Konstantinopel und die Meerengen), Moskau 1925. 
litik kein anderes Ziel im Orient hatte, als die Erhaltung des statu quo. »On se figure«, sagte Giers zu Ribot, "que nous convoitons Constantinople. Nous pensons au contraire que rien ne serait plus fâcheux pour la Russie que de déplacer son centre de gravité. Que deviendraient nos provinces du Nord et SaintPétersbourg? Nous désirons que les Turcs restent préposés à la garde des Détroits. $\kappa^{31}$

Mithilfe dieser Dokumente haben wir die verschiedenen Darstellungen von Konstantinopel, die in der russischen Kultur und politischen Vorstellungswelt existierten, sowie die verschiedenen Visionen von Jerusalem aufgezeigt. Die Staatsgewalt sowie die russischen Denker des 19. Jahrhunderts haben besonders Konstantinopel-Zargrad betont. Das Volk, besonders die Bauernschaft, interessierte sich dagegen besonders für Jerusalem. Immerhin waren beide Städte im russischen Kollektivbewußtsein präsent und durch ein gemeinsames Schicksal verbunden. In unseren Ausführungen haben wir den Vorstellungen, Ideen und Mythen große Wichtigkeit eingeräumt. Dies läßt sich durch die große Rolle rechtfertigen, welche das Imaginäre im Vordringen Rußlands im Nahen Osten gespielt hat.

${ }^{31}$ Documents diplomatiques français, Série I (1871-1900), Bd. 9, Nr. 76, S. 111. Im Laufe des Kriegs wurde die Frage von Zargrad und von Jerusalem wieder aufgeworfen. 1915 schlug Erzbischof Antonij Khrapovicki vor, Zargrad den Griechen zu überlassen, ein neues Byzantinisches Reich zu bilden und Palästina sowie Syrien mit Rußland verbinden: Antonij KHRAPOVICKI, Tschej dolschen bit Konstantinopl? (Wem soll Konstantinopel gehören?), Kharkov 1915, S. 8-11. Am 3. März 1915 vertraute Zar Nikolaus II. dem französischen Botschafter Maurice Paléologue an, daß er beschlossen hatte, auf eine radikale Art das Problem von Konstantinopel und der Meerengen zu lösen: „Ich darf meinem Volk dieses Geschenk für seine Opfer und für die zahlreichen Toten nicht verwehren und muß ihm die Verwirklichung seines historischen Traums erlauben. Deswegen habe ich den Entschluß gefaßt, von dem ich im November sprach. Dieser Entschluß ist einzig und zugleich durchführbar: Die Stadt Konstantinopel soll meinem Reich angeschlossen werden.« Zitiert nach ADAMOV, Konstantinopel und die Meerengen, S. 109f. Interessant ist es, einerseits den Originaltext der Memoiren von Paléologue mit diesem Text Adamovs zu vergleichen, andererseits den Text des französischen Botschafters dem russischen Archiv gegenüberzustellen. So wurde ersichtlich, ob die Erklärung des Zaren, zitiert zuerst von Paléologue, dann von Adamov, zu einem russischen Mythos gehört, der zuerst von einem Franzosen, dann von einem Sowjetschriftsteller und von beiden mit eigenen Ansichten präsentiert wurde; oder ob Nikolaus II. Konstantinopel tatsächlich annektieren wollte, um aus dem Traum eine Wirklichkeit zu machen. Weder die russischen Archive, noch aktuelle Recherchen haben es ermöglicht, diese Frage zu erhellen. Auf alle Fälle ist der Gedanke an eine Wiedereroberung Konstantinopels und Jerusalems im politischen Volksglauben lebendig geblieben, sogar während der Sowjetperiode. Anläßlich des 500 . Jahrestages der Unabhängigkeit der russischen Kirche, 1948, schlug der Ex-Seminarist Stalin vor, den Sitz des Ökumenischen Patriarchen von Konstantinopel nach Moskau zu verlegen und dem russischen Patriarchen den Titel des Ökumenischen Patriarchen zu verleihen. Siehe "Doklad Soveta po delam Russkoj Pravoslavnoj Zerkvi pri Sovete Ministrov, 14 fevralja 1947 goda« (Bericht des Rats der Angelegenheiten der russischen Orthodoxen Kirche beim Ministerrat der Sowjetunion, Moskau, den 14. Februar 1947), zitiert nach: Rossiaj v Svjatoj Zemle (Rußland im Heiligen Land), Moskau 2000, Bd. I, S. 33. 


\section{Die erste Niederlassung des Russischen Reichs in Palästina: die kirchliche Mission in Jerusalem}

In der französischen Geschichtsschreibung finden wir die Auffassung, wonach die russische kirchliche Mission 1847 in Jerusalem als Reaktion gegen die Gründungen des englisch-preußischen Bistums 1841 und des lateinischen Patriarchats von Jerusalem 1847 zu verstehen war $^{32}$. Der Außenminister Nesselrode schreibt am 13. Juni 1842 an Nikolaus I.: "Der Gedanke an einen Schutz und eine Unterstützung der Kirche in Palästina ist lange unerfüllt geblieben, wegen unserer Angst vor den Verdächtigungen der Hohen Pforte und des Neids der anderen christlichen Länder. Jetzt, nachdem ein protestantischer Bischof in Jerusalem ernannt worden ist und sich die anglikanischen Missionare zahlenmäßig verstärkt haben, wird unser Ziel immer wichtiger ${ }^{33}$. Man findet denselben Gedanken in einem Brief des Priesters Porphirij Uspenski, dem ersten Verantwortlichen der russischen kirchlichen Mission: "Alle behaupten, ich sei im Heiligen Land wegen des Auftretens eines protestantischen Bischofs ernannt worden. ${ }^{34}$ Unseres Erachtens nach liegen die beiden Ereignisse durch Zufall im selben Zeitraum. Sie haben vielleicht die russische Initiative beschleunigt, jedoch nicht hervorgerufen.

Die wichtigsten Ursachen für die Gründung der russischen kirchlichen Mission in Jerusalem sind: die expansionistische, auf der Ideologie "OrthodoxieAutokratie-Nationalismus « beruhende Außenpolitik Nikolaus' I.; das aufkommende Interesse der Öffentlichkeit für die Nahostreisen; das Erwachen des missionarischen Gedanken in den Jahren 1830-1840; der Wille, das Patriarchat von Jerusalem zu kontrollieren und die katholische sowie die protestantische Propaganda zu bekämpfen.

In den Jahren 1820-1830 besuchten nur wenige russische Pilger das Heilige Land, aber die höheren Gesellschaftsschichten begeisterten sich für die Reiseberichte im Nahen Osten. Daschkov, Sondergesandter Alexanders I. um 1820; Murawiew, Diplomat und religiöser Schriftsteller (zum ersten Mal 1830); Norov, der zukünftige Erziehungsminister, 1835; und weitere haben die Heiligen Stätten beschrieben, besonders den griechischen und den arabischen Klerus, sowie die

${ }^{32}$ Näheres über diese Gründungen bei HAJJAR, L'Europe et les destinées du Proche-Orient, S. 373-458, 482-514.

${ }^{33}$ Vsepoddaneischij doklad vize-kanzlera grafa K.B. Nesselrode ob otpravlenii duchovnovo liza v Ierusalime. Rossiaj i Svjatoj Zemle (Bericht des Grafen K. von Nesselrode an Nikolaus II. Rußland im Heiligen Land), Moskau 2000, Bd. II, S. 12f.

${ }^{34}$ Wassilij KHITROwO, Russkaja duchovnaja missija v Ierusalime. Rossiaj v Svjatoj Zemle (Die russische kirchliche Mission in Jerusalem. Rußland im Heiligen Land), Moskau 2000, Bd. II, S. 376. 
problematischen Verhältnisse zwischen Katholiken und Orthodoxen ${ }^{35}$. Sie haben auch die schwierigen Zustände der russischen Pilgerfahrten beschrieben. Durch die Schilderung ihrer Privatreisen oder auch ihrer kaiserlichen Dienstreisen haben sie in Rußland das Interesse für den Orient erweckt. Sie haben auch die Notwendigkeit unterstrichen, die Orthodoxie im Orient durch eine russische kirchliche Mission zum Aufleben zu bringen.

Die Jahre 1830-1840 waren für die missionarische Tätigkeit günstiger. Weder die Toleranzpolitik Katharinas II., die im Spruch »Genau wie Gott alle Glaubensüberzeugungen auf Erden duldet, so wünschen auch wir $\mathrm{zu}$ handeln und darin seinen heiligen Willen zu befolgen ${ }^{36}$ zum Ausdruck kam, noch die Befürwortung der Heiligen Allianz durch Alexander I. und den darin implizierten Gedanken einer universalen Christenheit hatten den missionarischen Gedanken fördern können. Dagegen begünstigte Nikolaus I. die Tätigkeit der Kirche im Sinne einer »Russifizierung" der nichtchristlichen und nichtrussischen Völker. Die bereits bestehenden Missionen wurden unterstützt und neue, unter anderem die Jerusalemer Mission, gegründet.

Doch konnte diese Mission als »normal« erscheinen, zumal an einem Ort, wo sich die ältesten orthodoxen Patriarchate, nämlich jene von Konstantinopel, Jerusalem, Antiochia, und Alexandria, befanden? Konnte diese Mission als »normal« erscheinen, in einer Region, in welcher Rußland eine vorrangige politische, religiöse, diplomatische Rolle zu spielen beabsichtigte?

Bis in die dreißiger Jahre des 19. Jhs. verliefen die Beziehungen zwischen dem griechisch-orthodoxen Klerus und Rußland problemlos. Das gegenseitige Interesse bewog übrigens beide zu einer engen Zusammenarbeit. Das Jerusalemer Patriarchat betrachtete Rußland als ein orthodoxes Land, welches nicht nur imstande war, der griechischen Hierarchie Geldhilfe für den Unterhalt der Heiligen Stätten und besonders des Heiligen Grabs zu bringen, sondern auch dazu verpflichtet war $^{37}$. Andererseits war Rußland in den Augen der Griechen eine politische Macht, die imstande war, Druck auf das osmanische Reich auszuüben

${ }^{35}$ Dimitrij V. DASCHKOW, Puteschestvie po Grezii i Palestine. Severnie sveti (Die Reisen in Griechenland und in Palästina, in: Die Blumen des Nordens), Sankt Petersburg 1826; Andrej N. MURAwIEW, Puteschestvie vo svjatie mesta v 1830 (Die Reise nach den Heiligen Stätten um 1830), Sankt Petersburg 1832; Awraham. S. NoROV, Puteschestvie po svjatoj zemle v 1835 (Die Reise ins Heilige Land um 1835), Sankt Petersburg 1838.

${ }^{36}$ Zitiert nach Paul EvDOKIMOV, L'orthodoxie, Paris 1979, S. 166.

${ }^{37}$ Nach dem Moskauer Brand von 1808 hatte das Jerusalemer Patriarchat ca. 7,5 Millionen Rubel Schulden. 1818 wurde in Moskau eine Vertretung des Jerusalemer Patriarchats gegründet, mit Sitz in der Kirche des Apostels Philippus im Zentrum der Stadt, und mit der Befugnis, bei den Gläubigen Kollekten für das Heilige Land zu sammeln. Der griechische Erzbischof Hierothäus bat 1835 den Heiligen Russischen Synod um die Erlaubnis, in allen Kirchen einen Becher aufzustellen, damit jeder Gläubige einige Kopecks für das Heilige Grab einwerfen könnte. In fünf Jahren konnte dieser Erzbischof mehr als 348000 Rubel einnehmen. Siehe: Erzpriester Nikodim RoTov, Istorija russkoj duchownoj missii (Geschichte der russischen kirchlichen Mission in Jerusalem), Serpuchow 1997, S. 62-65. 
und die Griechen in ihren ständigen Konflikten mit den Katholiken zu unterstützen. In mehreren Berichten aus den Jahren 1829 und 1831 unterstrich die russische Botschaft in Konstantinopel die Notwendigkeit, ihre griechischen Schützlinge besser in ihrem Kampf gegen Katholiken und Armenier zu unterstützen. 1836 stellte die Bruderschaft vom Heiligen Grab ein Gesuch gegen die Armenier an Nikolaus I., sowie an den Heiligen Russischen Synod und an den Metropoliten Philaret von Moskau. 1837 erhielt der russische Botschafter in Konstantinopel, Butenew, einen neuen Firman [osmanischer Erlaß], der den Griechen die Vorrechte über die Heiligen Stätten zurückgab ${ }^{38}$.

Andererseits war Rußland nicht geneigt, seine Beziehungen zu den Griechen zu ändern: Weder der Heilige Synod, noch das Außenministerium hatten diese Beziehungen in Gang gebracht; sie hatten bloß die Bittgesuche der Jerusalemer Patriarchen beantwortet. Gegen Ende der 1830er Jahre jedoch, nach der syrischägyptischen Krise von $1839^{39}$, wurde Rußland gezwungen, seinen Platz in diesem Raum einzunehmen, um seine Schirmherrschaft über die Orthodoxie zu bekräftigen, aber auch um seine Beziehungen mit der Jenusalemer griechischen Hierarchie neu zu ordnen.

Im Jahre 1839 unternahm der religiöse Schriftsteller und Diplomat Andrej N. Murawiew seine zweite Reise in den Nahen Osten. Nach seiner Rückkehr verfaßte er für das russische Außenministerium einen Bericht, in dem er die Gründung einer russischen Mission mit folgenden Hauptaufgaben vorschlug: die Sicherheit der russischen Pilger zu gewähren; das griechische Patriarchat in Jerusalem zu kontrollieren; die Propaganda der anderen christlichen Konfessionen zu bekämpfen. Der Sitz sollte, Murawiew zufolge, auf dem Berge Zion sein. Die Moschee, die am Ort des Abendmahls und der Herabkunft des Heiligen Geistes stand, sollte den Orthodoxen überbracht werden wentweder in Form einer Schenkung, oder mittels eines Kaufvertrags, denn dies ist ein heiliger Erwerb den man um allen Preis besitzen muß, trotz des Widerwillens einiger Mohammedaner. ${ }^{40}$

Der russische Botschafter M. Titow kritisierte die Murawiewer Vorschläge scharf ${ }^{41}$. Schließlich genehmigte der Zar Nikolaus I. den Plan einer »russischen Niederlassung in Jerusalem ${ }^{42}$. Er tat dies unter dem Einfluß des russischen Konsuls in Beirut, Basili, und der Eingaben der russischen Kirchenoberen sowie v.a. des Metropoliten von Woronesch, aber auch unter dem Einfluß des Oberprokurators des Heiligen Synods, Nikolai A. Protasow und auf Grund des Be-

${ }^{38}$ Ibid. S. $69 \mathrm{f}$.

${ }^{39} \mathrm{Zu}$ diesen Ereignissen siehe HAJJAR, L'Europe et les destinées du Proche-Orient, S. 179194, 261-324.

40 Alexander POPOV, La question des Lieux Saints de Jérusalem dans la correspondance diplomatique russe du XIX ${ }^{e}$ siècle. Première partie, 1800-1850, Sankt Petersburg 1910, S. 243-253.

${ }^{41}$ lbid. S. 253-255.

42 »Bericht des Grafen K. von Nesselrode ...« in: Rußland im Heiligen Land, Bd. II, S. 11. 
richts des russischen Außenministers, des Grafen Karl Robert Nesselrode ${ }^{43}$. Dieser Bericht informierte über die Ankunft des Erzpriesters Porphirij Onuphrij, des amtierenden Priesters an der russischen Botschaft in Wien, in Jerusalem. Letzterer sollte den Heiligen Synod und das russische Außenministerium über die Erfordernisse der Orthodoxie in Palästina unterrichten und als Bindeglied zwischen der griechischen und der russischen Hierarchie wirken; er sollte außerdem die damalige Situation beobachten und darüber berichten ${ }^{44}$. Der Priester Uspenskij, der eher Gelehrter als Diplomat war, blieb acht Monate in Palästina, vom 20. Dezember 1843 bis Anfang August 1844. Nach diesem »PilgerAufenthalt" schlug er vor, "eine Vertretung der russischen Kirche bei den Kirchen von Palästina, Alexandria und Antiochia oder ein russisches Kloster zu gründen « im Interesse »der engen Union der Kirchen von Rußland und Palästina; der ewigen Fürbitte für Rußland und sein Herrscherhaus; der Gaben der russischen Kirche für die Grabeskirche und der geheimen Gaben der russischen Gläubigen für die armen Christen in Palästina; der moralischen Kontrolle der russischen Pilger und ihrer Unterstützung gegenüber den lokalen Behörden; der wissenschaftlichen Forschungen ${ }^{45}$. Der endgültige Entschluß für die Gründung der russischen kirchlichen Mission wurde am 31. Juli 1847 getroffen $^{46}$.

Erzpriester Porphirij wurde als Leiter dieser Stiftung nach Jerusalem geschickt, mit den Anweisungen des Außenministeriums, »die griechische Hierarchie und den lokalen arabischen Klerus zu beeinflussen.« Die erste russische Mission blieb bis Mai 1854 in Jerusalem. Während dieser Zeit unternahm der Erzpriester Porphirij verschiedene Reisen und wissenschaftliche Untersuchungen in der Region ${ }^{47}$. Khitrowo ist der Meinung, daß die erste Mission zwecklos gewesen war, denn, so schreibt er, "sie hat unsere Angst vor dem griechischen Patriarchat gezeigt [...] Die Beziehungen des Patriarchats mit dem Lokalklerus, die Tätigkeiten der Katholiken und der Protestanten blieben den Russen unbekannt. $\varkappa^{48}$ Man kann annehmen, daß etwas Wahres an diesen Äußerungen Khi-

${ }^{43}$ „Instrukzija (soveti) Ministra inostranich Del archimandritu Porifriu, 2 nojabrja 1843 « (Die Anweisungen des Ministers der äußeren Angelegenheiten an den Erzpriester Porphirij, am 2. November 1843), in: Rußland im Heiligen Land ... Bd. II, S. 15f.

44 "Zapiska archimandrita Porfiniaja Poslanniku v Konstantinopl V.P. Titovu« (Notiz des Erzpriesters Porphirij an den russischen Botschafter in Konstantinopel V.P. Titow, am 6. Januar 1845), in: Rußland im Heiligen Land, Bd. II, S. 16-23.

${ }^{45}$ RoTOV, Geschichte der russischen kirchlichen Mission in Jerusalem, S. 93

${ }^{46}$ "Instrukzija MID natschalniku russkoj duchovnoj missii $\mathrm{v}$ Ierusalime archimandritu Porfiriu, 28 avgusta 1847 « (Anweisungen des Ministeriums des Äußeren an den Erzpriester Porphirij Uspenskij, Leiter der russischen kirchlichen Mission in Jerusalem, den 28. August 1847), in: Rußland im Heiligen Land, S. 25-27.

${ }^{47}$ Siehe die Bibliographie der Werke des Uspenskij bei Polixronij SIRKU, Opisanie bumag episkopa Porfirija (Uspenskogo) (Beschreibung des Archivs des Bischofs Porphorij [Uspenskij]), Sankt Petersburg 1891.

${ }^{48}$ KHITROwO, Russkaja duchownaja missiaja v lerusalime (Die russische kirchliche Mission in Jerusalem), in: Rußland im Heiligen Land, Bd. II, S. 375. 
trowos ist; man muß jedoch zugeben, daß Porphirij und seine Mitarbeiter einen ersten Versuch unternommen hatten, um mit den Griechen in Verbindung zu treten und die Lebensverhältnisse der russischen Pilger zu verbessern.

Die erste Mission wurde durch den Krimkrieg unterbrochen. Über die Ursachen dieses Kriegs gibt es zahlreiche Untersuchungen ${ }^{49}$. Wir wollen hier lediglich unterstreichen, daß es neben den politischen Interessen Englands, Rußlands und Frankreichs auch im eigentlichen Sinne religiöse Interessen gab: für Frankreich war es der Schutz der Katholiken; für Rußland die Behauptung der Weltstellung der Orthodoxie. Die Niederlage im Krimkrieg zwang die Regierung und die russische Intelligenz, ein neues Konzept für die Stellung Rußlands in Europa und im Orient zu entwickeln und auch das Bild zu revidieren, welches Rußland von sich selbst hatte. Nach dem Krimkrieg belebten die russischen Schriftsteller die alten Schemata und ideologischen Rechtfertigungen wieder. Sie mußten eine Neubildung der Mythen des »Heiligen Rußlands« ausarbeiten, des reinen, geistlichen, welterlösenden Rußlands, in einem Kampf für eine neue Zivilisation slawo-asiatischen Typs, welche die westliche Zivilisation ersetzen würde (Leontiew). Alle diese intellektuellen Vorstellungen gaben einen Ausgleich zum wirtschaftlichen und sozialen Rückstand Rußlands und versuchten, seine Angst vor Westeuropa zu verdecken. Paradoxerweise haben französische Intellektuelle die Schriftsteller Anatole Leroy-Beaulieu, Alfred Rambaud, Louis Léger, Eugène-Melchior de Vogüé, die die Meisterwerke von Turgeniew und Dostojewski übersetzt hatten - in den Jahren zwischen 1870 und 1880 diesen Mythos des »Mystizismus der russischen Seele« in die französische Kultur übertragen, einen Mythos, der ursprünglich gegen die Europäer, insbesondere gegen die Franzosen, gerichtet war ${ }^{50}$.

Die Verwaltung des Zaren Alexander II. führte ein Reformprogramm auf allen Ebenen des russischen Lebens, sowohl dem wirtschaftlichen als auch dem sozialen und religiösen, durch. Die "Orientfrage" wurde in der Außenpolitik ein vorherrschendes Thema. Graf Gortschakow, russischer Außenminister, fertigte 1857 für den Zar Alexander II. eine Vorlage an, in welcher er folgende Gedanken entwickelte: »Früher hatte Rußland im Orient einzig mit der Türkei zu tun; jetzt, nach dem Krimkrieg, sind wir verpflichtet, die europäischen Mächte mit einzubeziehen. $\ll^{51} \mathrm{Er}$ schlug die Wiederherstellung der russischen kirchlichen Mission in Jerusalem vor, allerdings sollte diese nun mehr Prestige und Voll-

${ }^{49}$ Dazu das Buch des sowjetischen Historikers Evgenij TARLÉ, Krimskaja voina (Der Krimkrieg), Moskau 1944. Luc MONNIER hat diese Frage ebenfalls untersucht, in seiner grundlegenden Monographie: Étude sur les origines de la guerre de Crimée, Genf 1977. HAJJAR hat in seinem Werk, L'Europe et les destinées du Proche-Orient, gezeigt, inwiefern die religiösen Probleme im Heiligen Land Ursache dieses Krieges waren.

${ }^{50}$ Siehe Elena ASTAFIEVA, L'Eglise orthodoxe russe dans les représentations des Français, de la fin du XVIII ${ }^{\mathrm{e}}$ siècle à 1917 , Diplomarbeit an der École pratique des Hautes Études $\left(5^{e}\right.$ Section), Paris 1998.

${ }^{51}$ RoTov, Geschichte der russischen kirchlichen Mission in Jerusalem, S. 121-123. 
machten erhalten. »Unsere Bestrebungen in diesem Raum«, schreibt Gortschakow, "zielen auf die Versöhnung der verschiedenen Völker des Orients. Die Russen sind bei allen beliebt: bei den Griechen [der griechischen kirchlichen Hierarchie], bei den Arabern, selbstverständlich bei den Slawen; die Lateiner, die Armenier, die Kopten, die Syrier und die Chaldäer ziehen uns den Griechen vor. $"$ " 2 Aus diesem Grund wünschte sich Gortschakow einen Bischof an der Spitze der russischen kirchlichen Mission in Jerusalem, um einen starken Eindruck zu machen ...

nicht nur in Jerusalem, sondern auch in Zargrad. In dieser Region hat noch niemand je einen russischen Bischof gesehen oder die Pracht unserer Gottesdienste bewundert [...] das beste der Orthodoxie, das heißt die russische Orthodoxie, ist unbekannt im Orient. Die Pracht unserer Gottesdienste und die Anwesenheit eines Bischofs werden nicht nur die Lateiner, sondern sogar die Griechen beeindrucken. Sie werden allen eine klare Sicht der wahren Orthodoxie im Orient geben. Dies ist sehr wichtig für uns, denn Jerusalem, diese heilige Stadt, ist der geistliche Mittelpunkt, nicht nur des Orients, sondern auch des Abendlandes; es ist ein Ort, der es uns erlaubt, die anderen antiken Patriarchate zu beeinflussen ${ }^{53}$.

Alexander II. stimmte ihm am 23. März $1857 \mathrm{zu}$, und die türkische Regierung bestätigte ihrerseits die Vorrechte der neuen russischen kirchlichen Mission in Jerusalem. Der neue Leiter der Mission, Kirill Naumow, Bischof von Melitopol, kaum 33 Jahre alt, erhielt vom Außenministerium als Hauptaufgabe, »den russischen Pilgern Schutz und Obdach im Heiligen Land zu geben und den Glaubensschwachen beizustehen. ${ }^{54} \mathrm{Ab}$ Anfang der sechziger Jahre betrieb die Mission zusammen mit dem Konsulat ${ }^{55}$ und dem Palästina-Komitee ${ }^{56}$ eine zielsichere Kauf-und-Bau-Politik. Man sah zuerst ein Gebäude für die Mission vor, dann Wohnstätten für die Pilger, schließlich die russische Kathedrale der Dreifaltigkeit ${ }^{57}$.

52 Ibid. S. 122.

53 Ibid. S. 123.

54 "Proekt otnoschenija Ministra Inostrannich Del k natschalniku Ierusalimskoj Duchovnoj Missii episkopu Kirillu Naumowu, 16 oktjabrja 1857« (Entwurf des Berichts des Außenministeriums für den Bischof Kirill Naumow, Leiter der russischen kirchlichen Mission in Jerusalem, am 16. Oktober 1857), in: Rußland im Heiligen Land, Bd. II, S. 55.

${ }^{55}$ Das russische Konsulat wurde 1858 in Jerusalem eröffnet.

${ }^{56}$ Dieses Komitee wurde 1859 unter der Schirmherrschaft des Großfürsten Konstantin, Bruder des Zaren Alexander II. und Marineminister, gebildet. Leiter war B. Mansurow. Es wurde 1864 zu einer Kommission für Palästina beim Außenministerium.

${ }^{57}$ Um diese Neubauten zu finanzieren, schlug Bischof Kirill Naumow den Verkauf von religiösen Devotionalien in Rußland vor, z.B. für nur zwei Kopeken Eheringe und Kreuze für Täuflinge, »in den heiligen Gewässern des Jordans gesegnet«. Der Metropolit von Moskau Philaret Drosdow verwarf diese Idee. Siehe RoTOv, Geschichte der russischen kirchlichen Mission in Jerusalem, S. 152. Dagegen stieß der Vorschlag von B. Mansurow auf großen Erfolg, besonders im Bauernvolk: »Jeder gläubige russische Orthodoxe gibt einmal im Jahr ein bis zwei Kopeken für das Heilige Land . Khitrowo berichtet, daß diese Sammlung mehr als eine Million Rubel in den Jahren 1858-1862 eingetragen hat. Siehe Boris MANSUROW, Prawoslawnie palomniki v Palestine (Die orthodoxen Pilger in Palästina), Sankt Petersburg 1881, S. 87. 
Nach sechs Jahren wurde der Bischof von Melitopol Kirill Naumow vom Erzmönch Leonid Kawelin abgelöst, welcher nicht länger als zwei Jahre in Jerusalem blieb. Wie sein Vorgänger wurde er aus der Heiligen Stadt vertrieben. Kirill Naumow war bei seinen russischen Mitbürgern - den lokalen Vertretern des Palästina-Komitees, der russischen Gesellschaft für Handel und Schiffahrt ${ }^{58}$, sowie bei den russischen Konsuln - eher unbeliebt, wohingegen Leonid Kawelin mit den Griechen des Jerusalemer Patriarchats und den übrigen Mitgliedern der Mission uneinig war. Das Palästinakomitee und die Gesellschaft für Handel und Schiffahrt versuchten dreißig Jahren lang, die kirchliche Mission unter die Kontrolle des Konsulats und des Außenministeriums zu bringen. Sie sollte der Obhut des Heiligen Synods entzogen werden, der seit den Reformen Peters des Großen ein einfaches Ministerium geworden war. Das Außenministerium zwang dem ältesten Patriarchat in Jerusalem die russische Mission auf, ohne um Erlaubnis für ihre Gründung ersucht zu haben, wie es von den Kanones der Ökumenischen Konzilien vorgeschrieben war $^{59}$.

Die griechische Hierarchie in Jerusalem trug ihre eigene Verantwortung in dieser Sache; allerdings hat diese Übertretung der kanonischen Regeln und dieser Höflichkeitsmangel den Beziehungen zwischen den Leitern der Russischen Mission und dem Jerusalemer Patriarchat geschadet. Die Geschichte der Russischen Mission gilt als gutes Beispiel dieser Beziehungen: Da sich die ganze orthodoxe Kirche unter dem Druck der staatlichen Gewalt befand, war die kirchliche Mission in Jerusalem ein politisches Instrument des orthodoxen Staates. Zweimal war die Schließung der Mission, 1866 und um 1878-1879, im Gespräch. Dank der starken Persönlichkeit des damaligen Leiters der Mission, des Archimandriten Antonin Kapustin (Leiter von 1865 bis 1894), konnte sie weitergeführt werden. Ihr Wirken wurde schließlich sogar verstärkt und gefördert unter dem Einfluß, aber auch unter der Aufsicht einer neuen Machtstellung Rußlands im Heiligen Land: der orthodoxen Gesellschaft für Palästina.

${ }^{58}$ Die russische Gesellschaft für Handel und Schiffahrt wurde 1856 in Sankt Petersburg gegründet.

59 Archimandrit Kern schrieb fast hundert Jahre nach der Gründung der russischen Mission in Jerusalem: „Wir haben die kanonischen Regeln vergessen oder vernachlässigt. Auf Grund dieser Regeln sind die Kompetenzgrenzen jedes Bischofs genau abgezeichnet. Der Bischof darf sich nicht in die Angelegenheiten einer fremden Diözese einmischen." Archimandrit Kern bezog sich auf verschiedene Kanones, unter anderem auf die des zweiten Ökumenischen Konzils. Siehe Kiprian KERN, O. Antonin Kapustin, archimandrit i natschalnik russkoj duchownoj missii v lerusalime (1817-1894) (Priester Antonin Kapustin, archimandrit und Leiter der russischen kirchlichen Mission in Jerusalem [1817-1894]), Belgrad 1934, S. 119 (russisch). 


\section{Die orthodoxe Gesellschaft für Palästina: eine private Körperschaft unter kaiserlicher Schirmherrschaft}

Der Gedanke, eine private Einrichtung zum Schutz und zur Aufrechterhaltung der Orthodoxie im Nahen Osten zu gründen, bestand in der russischen Gesellschaft seit den Jahren 1830-1840. 1847 schlug Erzpriester Porphirij Uspenski die Gründung einer orientalischen Gesellschaft vor. Diese sollte mittels privater Schenkungen Kirchen und Spitäler bauen, »um den russischen Pilgern und Armen im Nahen Osten zu helfen. ${ }^{60}$ Diese Idee wurde erst nach der Reise Vasili Nikolajewitsch Khitrowos im Nahen Osten verwirklicht. Der höhere Beamte des Finanzministeriums kam 1871 zum ersten Mal nach Palästina ${ }^{61}$. Er war von seiner Reise so sehr beeindruckt, daß er sich entschloß, dem Heiligen Land sein Leben zu widmen. Nach seiner Rückkehr sammelte Khitrowo Material über die Region und bildete eine »Palästina-Bibliothek«, die Grundlage zum bibliographischen Sammelwerk »Palästina und Sinai ${ }^{62}$. In diesem Band sammelte er mehr als hundert russische Werke aus dem 12. bis zum 19. Jahrhundert, die das Heilige Land betreffen, und ergänzte sie um russische Übersetzungen der wichtigsten Ausfuihrungen fremder Autoren zu diesem Thema ${ }^{63}$. Khitrowo hatte vor, alte Reisebeschreibungen von russischen und griechischen Pilgern in französischer Übersetzung zu veröffentlichen.

${ }^{60}$ Porphirij USPENSKI, Kniga bitija moego (Das Buch meines Lebens), Sankt Petersburg 1896, Bd. III, S. 449, 45If.

${ }^{61}$ In seinen Reisenotizen liest man seinen frühen Wunsch, Palästina zu besuchen: "Wie oft, als ich Kind war, nachdem ich mit meiner Matuschka (Mütterchen) die obligatorische Lesung der drei Passagen der Heiligen Schrift beendet hatte, träumte ich von Palästina, von Jerusalem [...]. Während der langen Winternächte lauschte ich den Schilderungen meiner Mutter über das Heilige Land [...]. Wie oft, bevor ich schlafen ging, habe ich die Gebete verrichtet. Im Kerzenlicht sah ich ein Kreuz, das eine Pilgerin mitgebracht hatte. Alle meine Gedanken trugen mich sehr weit, ins Morgenland, nach Jerusalem, zum Grabe Christi, auf Golgatha [...]. Viel Zeit ist seither verflossen. Und nun befand ich mich, der ich kein Kind mehr war, auch noch kein junger Mann, an Bord eines Schiffes und konnte sehen, wie kindliche Bilder Wirklichkeit wurden [...].« Zitiert von Alexej A. DMITRIEWSKI, Imperatorskoe Pravoslavnoe Palestinskoe Obschestwo (1882-1907) (Die kaiserliche orthodoxe Gesellschaft für Palästina und ihre Tätigkeit [1882-1907]), Sankt Petersburg 1907, S. 123.

${ }^{62}$ Wassili KhItrowo, Palestina i Sinai (Palästina und Sinai), Sankt Petersburg 1907, S. 123.

${ }^{6.3}$ Khitrowo war voller Bewunderung für das reiche Material der fremden Untersuchungen über Palästina. Er bedauerte die eher armen russischen Beiträge. »Mangels russischer Quellen sind wir genötigt, die fremde Literatur zu benutzen: die katholische, welche statutgemä $\beta$ nicht neutral bleiben kann gegenüber den orthodoxen, protestantischen und anderen Quellen [...]. Rußland ist doch die natürliche Erbin von Byzanz, dessen Legenden und Berichte in Rußland überliefert wurden und so wichtig sind für die Geschichte. Und Rußland blieb das einzige Land, welche die Orthodoxie in ihrer Wiege verteidigen sollte [...]. Deswegen ist es wichtig, alle Texte der russischen Schriftsteller zu kennen, denn sie sind authentisch [...].« KHITROwO, Palestina i Sinai, S. II-III. Zu jeder bibliographischen Note findet man eine abgekürzte Angabe über den Inhalt sowie kritische Noten von Khitrowo. 
Diese Ideen waren Teil eines sehr viel weitergehenden Plans. Am 3. Februar 1877 schrieb er an Antonin Kapustin:

Die Entwicklung der religiösen, politischen, wissenschaftlichen Interessen im Westen zeigt die Unwürdigkeit unserer Untätigkeit. Diese Untätigkeit kommt von unserem Unwissen, nicht etwa von unserem Unwillen [...]. Ich habe seit langem gedacht, wir sollten ein Palästinakomitee gründen, nicht etwa ein offizielles, sondern ein privates, nach dem Modell des Palestine exploration fund ${ }^{64}$. Wir sollten auf diesem Weg das Heilige Land erforschen, damit die Russen diese Gegend kennenlernen, und auch um die russischen Pilger, sowie alles Russische durch Bodenaufkauf und wissenschaftliche Veröffentlichungen, ganz besonders durch gute Reiseführer, zu unterstützen ${ }^{65}$.

Nach seiner Rückkehr von der zweiten Reise veröffentlichte er ein Buch über die Orthodoxie im Heiligen Land. Darin analysierte er die Einrichtungen der Katholiken und der Protestanten und kritisierte zugleich das russische Wirken in dieser Gegend. Er erinnerte daran, daß »Palästina wichtig ist für Rußland wegen seiner religiösen, politischen und moralischen Bedeutung. ${ }^{66}{ }^{6}$ Khitrowos Begegnung mit dem Großfürsten Sergius Anfang 1882 führte zur Gründung der orthodoxen Gesellschaft für Palästina, die ab 1889 den Namen »Kaiserliche orthodoxe Gesellschaft für Palästina« trug. Der Erfolg dieser Initiative läßt sich durch das Aufblühen der nationalistischen und patriotischen Bewegung nach dem Krieg von $1877 / 78$ erklären.

Dazu kam allerdings die Oberherrschaft des Bruders des Zaren Alexander III. und des Oberprokurators des Heiligen Synods, Konstantin Pobedonoschew: Beide bemühten sich um die Behauptung der russischen Nation, der Orthodoxie und der Autokratie. Die Palästinagesellschaft konnte sich weiter entwickeln, mit der Unterstützung der höheren Gesellschaft, insbesondere des Zaren selbst, der sich sogar als Mitglied einschreiben ließ. Laut ihrer Statuten (Ustaw) hatte die Gesellschaft drei Aufgaben:

1. die Verbreitung der Kenntnisse über die Heiligen Stätten in Rußland;

2. die Unterstützung der orthodoxen Pilger im Heiligen Land;

3. die Gründung von Schulen, Spitälern und Wohnstätten für die Pilger sowie die materielle Unterstützung der lokalen Bevölkerung, der Kirchen, Klöster und des Klerus ${ }^{67}$.

${ }^{64}$ Palestine Exploration Fund, eine englische, protestantisch gefärbte Gesellschaft, welche 1865 zum Ziel wissenschaftlicher, archäologischer Ausgrabungen gegründet wurde.

${ }^{65}$ DMITRIEVSKI, Die kaiserliche orthodoxe Gesellschaft für Palästina, S. 125.

${ }^{66}$ Wassili KHITROWO, Pravoslavie v Svajtoj Zemle (Orthodoxie im Heiligen Lande), in: Pravoslavnij Palestinskij Sbornik, Sankt Petersburg 1881, Bd. 1, S. 98.

${ }^{67}$ Der Paragraph I des Ustows der Orthodoxen Gesellschaft für Palästina wurde, zusammen mit den übrigen offiziellen Dokumenten der Gesellschaft im Verordnungsblatt veröffentlicht: Soobschenija Imperatorskogo Pravoslavnogo Palestinskogo Obschestwa (Verordnungsblatt der Kaiserlichen orthodoxen Gesellschaft für Palästina, 1901, Bd. XII, gekürzt: Verordnungsblatt). 
Die Beiträge der Mitglieder ${ }^{68}$, die privaten Schenkungen ${ }^{69}$, die Kollekten in den Kirchen, besonders am Palmsonntag ${ }^{70}$, bildeten die Haupteinnahmen der Gesellschaft $^{71}$. Überdies garantierte die höchstpersönliche Unterstützung des Großfürsten und der kaiserlichen Familie den hohen Status der Gesellschaft und eine staatliche Subvention zu ihren Gunsten. Bei der feierlichen Eröffnung der Gesellschaft am 21. Mai 1882 hatte sie ein Defizit von 50 Rubeln. 25 Jahre später, im Jahre 1907, nahm Nikolaus II. Kenntnis davon, daß die Gesellschaft über einen Besitz von über zwei Millionen Rubel verfügte sowie von acht Häusern für die Unterkunft von jährlich 10000 Pilgern, einem Spital, sechs Ambulanzen und 101 Schulen mit 10430 arabischen Schülern. In derselben Zeit gab die Gesellschaft 347 Bücher über Palästina heraus ${ }^{72}$.

Der Erfolg war unübersehbar. Vasili Khitrowos Bruder Sergius, russischer Botschafter in Bukarest, schlug 1887 die Gründung einer unabhängigen Bruderschaft für die Unterstützung der weltweiten Orthodoxie vor. Selbstverständlich sollte die Gründung dieser Bruderschaft vom orthodoxen Rußland und von der Palästinagesellschaft ausgehen. Sein Plan war, in jedem orthodoxen Land eine lokale Gesellschaft, mit einem gemeinsamen Programm »zur Erhaltung der or-

${ }^{68}$ Über den rechtmäßigen Status der Mitglieder, siehe Kapitel II, Abschnitt 13 bis 30 des Ustaws der Gesellschaft.

${ }^{69}$ Die genaue Untersuchung der Verordnungsblätter der Gesellschaft zeigh, daß die Beiträge der angefürten Schenker zwischen einem und drei Rubel lagen. Zugleich gab es auch Schenkungen von tausend Rubel. Die Mehrzahl der Schenker kam aus dem weißen Klerus.

${ }^{70}$ Am 23. August gab der Heilige Synod die Erlaubnis, jedes Jahr am Palmsonntag eine Kollekte für »die Heiligen Stätten in Palästina« zu organisieren. 1886 sammelte die Gesellschaft 129551 Rubel und im Jahr darauf 111942 Rubel. Der Klerus und die nationalen Presseorgane appellierten an die russischen Gläubigen, wdie Diener des Antichrists daran zu hindern, die orthodoxe Herde des Patriarchats zu verschiedenen Ketzereien oder zum Mohammedanismus zu bekehren [...] damit das russische Herz sich geistlich am Grabe Christi nähren kann." Vozvanie Vladiki Antonina, Ufimskogo episkopa, Ufimskie eparcharlnije vedomasti (Aufruf des Bischofs Antonij, von Ufa. Nachrichten von Ufa, 1901, Nr. 5, S. 1). Es handelt sich um die Blätter: Novoe Vremija; Zerkovnij Vestnik; Moskovskie Vedomosti; sowie um die lokale Bistumsblätter, wie z.B. Eparchalnije Vedomosti.

${ }^{7}$ Auf jeden Rubel (100\%), schrieb Khitrowo in seinem offiziellen Bericht von 1899/1900, kommen 70 Kopeken (70\%) von den Gaben der Gläubigen (insbesondere von der Sammlung am Palmsonntag); 13 Kopeken kommen aus den Beiträgen der Mitglieder der Gesellschaft (5 131 Mitglieder 1899/1900), 4 Kopeken kommen von den Zinsen der Aktien, und ein letzter Kopek stammt aus dem Verkauf der Veröffentlichungen des Vereins. Aus demselben Bericht geht hervor, daß die Gesellschaft 32 Kopeken (d.h. $32 \%$ ihrer Einkünfte) für die Unterstützung der Orthodoxie in Palästina und in Syrien ausgegeben hat (d.h. für den Bau von Schulen und Kirchen). In derselben Zeit hat die Gesellschaft 35 Kopeken für die Pilger, 8 Kopeken für wissenschaftliche Forschungen, und 25 Kopeken anderweitig ausgegeben. Jeder Pilger hat 12 Rubel und 38 Kopeken gekostet, jeder Schüler in einer arabischen Schule 23 Rubel und 21 Kopeken. Verordnungsblatt, 1901, Bd. XII, Nr. 1, S. I1f.

${ }^{72}$ Verordnungsblatt, 1907, Bd. XVIII, Nr. 3-4, S. 398f., $432 f$. 
thodoxen Reinheit der lokalen orthodoxen Gemeinschaften, und zur Rückkehr der verlorenen Kinder der Orthodoxie « zu gründen ${ }^{73}$.

Khitrowo sowie die übrigen Mitglieder der Gesellschaft, wie Dmitrij D. Smischliaev, sahen den Sachverhalt auf eine pragmatischere und weniger träumerische Art. Auf ihre Anregung hin wurden ab 1893 in fast allen russischen Diözesen lokale Ableger der Gesellschaft gegründet. Diese sollten auf lokalem Gebiet die Gaben und die Beiträge der Mitglieder sammeln, sowie für eine bessere Kenntnis des Heiligen Lands in der Bevölkerung sorgen ${ }^{74}$. Um diesen Aufgaben gerecht $\mathrm{zu}$ werden, schuf die Gesellschaft am 21. März 1883 drei Abteilungen:

1. eine erste, unter der Leitung von Fedor I. Kobeko, welche mit den wissenschaftlichen Arbeiten und Veröffentlichungen beauftragt wurde;

2. die zweite war unter der Leitung von Fedor I. Kornilov für die Unterstützung der russischen Pilger im Heiligen Land zuständig;

3. die dritte, mit Pawel A. Wasiltschikow an der Spitze, für die Erhaltung und den Schutz der Orthodoxie unter der Lokalbevölkerung in Palästina und Syrien.

Die Arbeit der ersten Abteilung begann mit der Gründung eigener Presseorgane für verschiedene soziale Schichten. Für das gebildete Publikum gab es ab 1881 die Orthodoxe Palästina-Sammlung ${ }^{75}$. Das Verordnungsblatt (ab 1885) ${ }^{76}$ interessierte sich besonders für die katholischen und protestantischen Zeitschriften, die im Heiligen Land erschienen, wie die Revue illustrée de Terre Sainte, Les Missions catholiques, usw. Für das meistens analphabetische Landvolk gab es die Lesungen über das Heilige Land ${ }^{77}$, Bücher kleinen Formats über verschiedene Themen wie Geographie, biblische Geschichte, Erzählungen von russischen Pilgern, usw. Die Mitglieder der Palästinagesellschaft oder der Klerus auf dem Land organisierten Lesestunden, manchmal in den Kirchen, brachten auf diese Weise den Bauern Grundkenntnisse bei und förderten die Pilgerbewegung. Ein offizieller Bericht der Gesellschaft gibt für 1902/1903 ungefähr 30000 solcher Lesestunden, in 5000 verschiedenen Ortschaften, mit über 5 Millionen Zuhörern an. Die Gesellschaft verbreitete über hundert Broschüren von den Lesungen über das Heilige Land, außerdem schickte sie 49210 Exemplare von diesen Lesungen in die Lokalvertretungen. In demselben Jahr verteilte die Gesellschaft

${ }^{73}$ Archiv Vneschnej Politiki Rossijskoj Imperii (AVP RF) (Außenpolitisches Archiv des russischen Reichs), f. 337/2, op. 873/1 Nr. 653, S. 1-4.

${ }^{74}$ DMITRIEVSKI, Die kaiserliche orthodoxe Gesellschaft für Palästina, S. 204.

${ }^{75}$ Russisch: Pravoslavnij palestinskij sbornik.

${ }^{77}$ Russisch: Tschtenija o Swjatoj Semle. 
644540 Palästinablätter ${ }^{78}$ kostenlos, sowie 640000 Bilder vom Heiligen Land, insgesamt also 1333750 Exemplare in allen Teilen Rußlands ${ }^{79}$.

Die zweite Abteilung für die Förderung der Palästina-Wallfahrten zeigte ebenso wie die erste eine intensive Tätigkeit. Die in der russischen Kultur beliebten Wallfahrten erlebten in der zweiten Hälfte des 19. Jhs. einen großen Aufschwung. Zuerst durch verschiedene materielle Begünstigungen: die Eisenbahn, das von der Gesellschaft gegründete Pilgerbüchlein; aber besonders durch die geistliche Erneuerung, deren Kennzeichen im Interesse an den Texten der orientalischen Kirchenväter lag. Ein weiterer Grund war die hesychastische Geistesbewegung sowie das Aufkommen des sogenannten startschestvo, d.h. des Staretz als geistlicher Mittelpunkt des heiligen Orts ${ }^{80}$. Es gab drei Wege nach Jerusalem:

1. Für die Mehrzahl der Pilger war Jerusalem der Endpunkt ihrer Wallfahrten. Sie mußten also vorher die russischen Heiligen Stätten besuchen: die bekanntesten Klöster, wie Potschaew, Kiew, Solowietsk, usw. und dann erst Jerusalem;

2. ein anderer Teil der Pilger begab sich über den Athos nach Jerusalem;

3. ein letzter Teil ging direkt nach Jerusalem.

In den Jahren 1810-1820 gab es verschiedenen Quellen nach gerade einmal 25 bis 100 Palästina-Pilger im Jahr, während es nach dem Krimkrieg zwischen 400 bis 600 pro Jahr wurden. Die Gründung der orthodoxen Palästina-Gesellschaft

${ }^{78}$ Russisch: Palestinskie Listki.

${ }^{79}$ Verordnungsblatt, Sankt Petersburg, 1904, Bd. XV, S. 14.

${ }^{80}$ Den Erzählungen eines russischen Pilgers nach legt ein Staretz die Philokalie in die Hand des Pilgers. Er erklärt diesem die Übung des immerwährenden Gebets oder Jesus-Gebets. Diese Erzählungen haben die Vorstellungen des Pilgers, des Landstreichers, des Irrläufers aus der russischen Kultur übernommen. Aus verschiedenen Quellen geht hervor, daß die Pilger während ihrer Pilgerfahrt das Jesus-Gebet: "Jesus Christus, erbarme Dich meiner" wiederholten. Dieses Gebet wurzelt in der hesychastischen Bewegung des vierzehnten Jahrhunderts. Über die Philokalie, über das immerwährende Gebet, und über die hesychastische Bewegung, siehe das Buch des Archimandriten Placide DESEILLE, La spiritualité orthodoxe et la Philocalie, Paris 1997; DERS., La prière de Jésus, Chèvetogne 1963; und: Hilarion ALFEYEV, Mystère de la foi, Paris 2001. Über die Erzählungen eines russischen Pilgers siehe Michel EVDOKIMOV, Pèlerins russes et vagabonds mystiques, und die Zeitschrift Symbole, 1992, deren Heft 27 ganz diesem Thema gewidmet ist. Placide Deseille erklärt den Begriff Hesychasmus folgenderweise: "L'Hésychia, ou quiétude, doit être entendue ici selon plusieurs niveaux. En un premier sens, elle signifie la solitude et le silence matériels, qui favorisent le recueillement de l'âme. En un second sens, elle désigne le calme intérieur qui procure la nepsis. Ce mot grec, qui signifie la sobriété (spirituelle), désigne la vigilance à l'égard de pensées, c'est-à-dire des suggestions mauvaises que les passions font naître dans l'âme, et, plus largement, l'exclusion de toute activité de l'imagination et du discours intérieur dans la prière. Enfin, elle exprime la paix de l'âme rassemblée en elle-même, la douceur intime qu'elle éprouve sous l'action de l'Esprit saint.« (DESEILLE, La spiritualité orthodoxe, p. 7). 
veranlaßte die Sendung von mehr als 6000 Pilgern in den 1890er Jahren, und von mehr als $10000 \mathrm{im}$ ersten Jahrzehnt des 20 . Jahrhunderts ${ }^{81}$. Das »einfache Volk « (die Bauern und die armen Stadtbewohner) bildeten $90 \%$ der Pilger; der Klerus 3,5\% ; die Vertreter des Adels $3 \% ; 66 \%$ der Pilger waren Frauen ${ }^{82}$.

Die meisten Pilger kamen aus Zentralrußland und der Wolgagegend ${ }^{83}$. Im Jahre 1883 gab die Palästinagesellschaft das »Pilgerbüchlein« heraus, welches 75 Rubel kostete (1820 kostete eine Reise nach Jerusalem 500 Rubel). Die meisten Bauern konnten sich das Büchlein natürlich nicht leisten, da das Jahreseinkommen einer mittleren Familie ohne Vieh in der Woronescher Gegend besipielsweise aus 65 Rubeln bestand ${ }^{84}$. Aus diesem Grund gingen die Pilger zu Fuß von einer Heiligen Stätte zur anderen. Diese lang andauernden Fußmärsche waren sehr mühsam, manchmal sogar tödlich. Dabei war der Gedanke des Leidens, und der Hoffnung, als Märtyrer im Heiligen Land zu sterben, den Gläubigen vertraut ${ }^{85}$.

Die Gründung der Schulen und der Spitäler, die dritte Aufgabe der Palästinagesellschaft, war die schwierigste. Zuerst fehlte es an qualifizierten Spezialisten, sowohl in der Lokalbevölkerung vor Ort als auch unter den Russen. Die Lehrer mußten imstande sein, nicht nur in ganz ungewohnten Verhältnissen ihr Amt zu verrichten, sondern auch ein neues pädagogisches System aufzubauen. Die »russischen Schulen« zielten hauptsächlich darauf, den arabischen Kindern in Palästina und in Syrien die Grundbegriffe des orthodoxen Glaubens beizubringen. Das Studium der arabischen Sprache war unentbehrlich, um den Schülern die Teilnahme an den religiösen Zeremonien zu ermöglichen. Das Studium der russischen Sprache nahm einen großen Platz in den Schulen der Palästinagesellschaft ein. In den Augen der Leiter der dritten Abteilung sollten die Kinder die Möglichkeit haben, wenigstens eine Fremdsprache zu erlernen. Auf diese Weise

${ }^{81}$ Quellen für die Jahre 1820-1850: Dmitrij V. DASCHKow, Puteschestvie po Grezii i Palestine, S. 225, Mihail D. WoLKoNSKIJ, Zapiski palomnika 1859 (Notizen eines Pilgers 1859), Sankt Petersburg 1860, S. 118 . Für die Jahre 1860-1900; Wassili N. KHITROWO, Kakimi putami idut palomniki v Swjatuu Zemlu (Die Wege der Pilger zum Heiligen Land), in: Verordnungsblatt 1901, Bd. XII, S. 312.

${ }^{82}$ KHITROWO, Die Wege der Pilger, S. 317.

${ }^{83}$ Ottschet Imperatorskogo palestinskogo Obschestwa 1908/1909 (Bericht der Kaiserlichen orthodoxen Gesellschaft für Palästina, 1908/1909), Sankt Petersburg 1911, S. 99-109. Um die Zahl der Wallfahrten ins Heilige Land besser einordnen zu können, sei erwähnt, daß in Rußland im Jahre 1897 auf eine Gesamtbevölkerung von 125668180 Einwohnern 87382000 Orthodoxe fielen.

${ }^{84}$ Zum Vergleich: eine Familie mit fünf Kühen aus derselben Gegend kam auf etwa 1000 Rubel. Siehe Istorija narodnogo chosajstwa SSSR (Geschichte der sowjetischen Wirtschaft), Moskau 1948. Bd. II, S. 78.

${ }^{85}$ Alexej A. DMrTRIEwSKI, Sowremennoe russkoe palomnitschestwo v Swjatuu Semlu. Trudi Kiewskoj duchownoj Akademii (Die russischen Pilger im Heiligen Land. Werke der Kiewer geistlichen Akademie), Kiew 1903, Nr. VI, S. 290f.; Medizinskij ottschet obschestwa za 1901/1902 (Medizinischer Bericht der Palästinagesellschaft, 1901/1902), in: Verordnungsblatt, 1903, Bd. XIII, S. 199. 
konnten die Kinder ihren Studiengang in zwei Schulen in Nazareth, Beit-Jala oder sogar in Rußland weiterführen. Schließlich, trotz aller Beteuerungen der Leiter der Palästinagesellschaft hinsichtlich des apolitischen Charakters der »russischen Schulen ${ }^{86}$, war die russische Sprache ein Mittel der »Russifizierung « der lokalen Bevölkerung. $\mathrm{Zu}$ Weihnachten und am Geburtstag des Zaren sangen die Schüler die russische Nationalhymne und die russischen Gebete. In den Klassenräumen hingen die Bilder der Mitglieder der kaiserlichen Familie. Jede Schule besaß eine russische Fahne, was den Kindern und den Eltern den Eindruck gab, dem »allmächtigen Rußland« anzugehören und unter dem Schutz des Zaren zu stehen.

In den Jahren nach 1910 begannen die Leiter des Außenministeriums, das Schulsystem der Palästinagesellschaft mit seinen allzu traditionellen Methoden zu kritisieren. Man schlug vor, die Schulstruktur zu ändern, damit sie »den Erwartungen der Zeit und des Lebens « besser gerecht werde ${ }^{87}$. Diese Sicht des Außenministeriums entsprach ebenfalls der Meinung der lokalen Bevölkerung, für die es wichtiger war, Französisch oder Englisch und andere »nützliche« Fächer statt Russisch zu erlernen. Das neue Programm für die russischen Schulen wurde vom Außenministerium 1914 eingeführt, konnte aber wegen der Kriegserklärung und der politischen Reformen nicht durchgeführt werden. Es ist interessant festzustellen, daß Rußland in den achtziger Jahren sein Schulsystem im Heiligen Land auf das Studium der arabischen und der russischen Sprache und des Gottesgesetzes aufgebaut hatte. Rußland wollte auf diese Weise die orthodoxen Werte in dieser Gegend wahren. Nun, Anfang des 20. Jahrhunderts, sah sich Rußland gezwungen, dem »Zeitgeist" nachzugeben und die »nützlichen « weltlichen Fächer, wie Englisch, Französisch, die Naturwissenschaft und Geschichte einzuführen.

Die Tätigkeiten der Palästinagesellschaft - sie stellte regelrechte $»$ Regimenter « von russischen Pilgern im Nahen Osten auf - rief die Furcht der europäischen Diplomatie hervor. Frankreich betrachtete sich als Beschützer aller Katholiken in der Gegend; so bat z.B. der französische Außenminister Ribot seinen russischen Kollegen, er solle Druck auf die Palästinagesellschaft ausüben, um den russischen Konsul in Jerusalem abzulösen, da er ein aktives Mitglied der Gesellschaft war $^{88}$. Die Beziehungen zwischen Frankreich und Rußland im Nahen Osten blieben verwickelt, auch nach dem Abschluß der russischfranzösischen Allianz Anfang der 1890er Jahre. Die französischen Diplomaten waren in ihren Ansichten geteilt. 1898, kurz vor dem Besuch von Wilhelm II. im

${ }^{86}$ Siehe die zahlreichen Berichte der Verantwortlichen der Palästinagesellschaft, z.B. Ottschet P.A. Wasiltschikowa, 19 dekabraja 1885. Ottschet Obschestva za 1885-1886 godi (Bericht des P.A. Wasiltschikow, den 19. Dezember 1885. Bericht der orthodoxen Palästinagesellschaft, 1885-1886), Sankt Petersburg 1886, S. 123-178.

${ }^{87}$ Über das Schulsystem in Palästina und Syrien, siehe Derek HOPWOOD, The Russian presence in Syria and Palestine. Church and politics in the Near East, Oxford 1969.

${ }^{88}$ Documents diplomatiques français, Série I, Bd. XIII, Nr. 16, S. 30; Bd. XIV, Nr. 14, S. 25. 
Nahen Osten, stellte sich letzterer als der neue Schirmherr der Katholiken in Palästina dar. Der französische Botschafter in Sankt Petersburg, Montebello, wünschte, Frankreich und Rußland sollten gemeinsam den deutschen Anmaßungen im Nahen Osten entgegentreten ${ }^{89}$. Dagegen betrachtete der französische Botschafter in Konstantinopel, Paul Cambon, diese Aktion als »unnötig« und sogar als "gefährlich «" ${ }^{90}$.

Wie nahm man dieses Problem in Sankt Petersburg wahr? Die russischen Diplomaten zögerten nicht, die geringste Gelegenheit zu nützen, um die russische Vorherrschaft in der Gegend zu behaupten und um den alt-russischen Gedanken zu verbreiten, daß »menschlich und providentiell gesehen die Zukunft des Orients nach und nach in die Hände Rußlands gleiten wird. ${ }^{91}$

Der Erste Weltkrieg und dann die Oktoberrevolution haben die Situation Palästinas und Rußlands völlig verändert. Die Beziehungen des letzteren zum Heiligen Land wurden unterbrochen. Die russisch-kirchliche Mission in Jerusalem blieb bis 1948 der russisch-orthodoxen Kirche im Ausland untergeordnet. Die kaiserliche Palästinagesellschaft ihrerseits wurde in eine Palästinagesellschaft innerhalb der Akademie der Wissenschaften umgewandelt, mit einem einzigen Ziel: die historische und soziologische Erforschung Palästinas und des Nahen Ostens.

1992 bekam die Palästinagesellschaft ihren ursprünglichen Namen zurück. Sie wurde zu einer öffentlichen internationalen Organisation, mit dem Zweck, wissenschaftliche, geistliche, diplomatische sowie kulturell-erzieherische Beziehungen zwischen dem russischen Volk und den Völkern des Nahen Ostens und des Mittelmeerraums herzustellen ${ }^{92}$. Die Tatsache, daß der ursprüngliche Name wieder gewählt wurde, mit seiner historischen Bedeutung und deren symbolischen Werten (»Kaiserlich und Orthodox«), sowie die Nominierung von Ehrenmitgliedern mit engen Verbindungen zu den politischen und religiösen Kreisen (der russische Patriarch, Alexis II., hat sogar akzeptiert, das Komitee der Ehrenmitglieder zu leiten), und auch der offizielle Diskurs der Gesellschaft zeigen, daß die geistlichen und religiösen Vorstellungen und die geopolitischen Konstruktionen, die einst das russische Kollektivbewußtsein inspirierten, in der russischen Gesellschaft heute wieder aktuell werden.

${ }^{89}$ Ibid. Série I, Bd. XIV, Nr. 247, S. 368.

${ }^{90}$ Ibid. Nr. 292, S. 454.

${ }^{91}$ AVP RF, F. 180, op.517/2, Nr. 7693, S. 70.

${ }^{92}$ Rossijskaja gazeta (Russische Zeitung), 26. 05. 1992, Nr. 119 (455). 


\section{La présence imaginaire et réelle de la Russie au Moyen-Orient, dans la deuxième moitié du XIX siècle}

Jérusalem et Constantinople, deux villes saintes, ont occupé une place importante dans l'imaginaire russe pendant des siècles, mais si les hommes politiques et les intellectuels russes étaient préoccupés par l'idée de la libération de Tsargrad, le peuple, les paysans allaient pour se prosterner devant le Tombeau de Jésus Christ.

À partir des années 1840, la Russie, comme les autres pays européens, s'installe en Palestine, en fondant la Mission ecclésiastique, mais "l'entrée massive« de l'Empire dans cette région date des années 1880 avec la création de la Société Impériale Orthodoxe de Palestine, qui commence à diffuser l'information sur la Terre Sainte pour tous les groupes sociaux en Russie et à construire en Palestine des écoles et des hôpitaux pour la population locale et des maisons pour les pèlerins russes. L'article est consacré à l'analyse de l'activité de la Société Impériale en Palestine. 